\title{
TEACHING AND LEARNING
}

\section{Managing Small Group Activities in Multiple Breakout Rooms as a Solo Instructor}

\author{
ZAHRA A. PREMJI \\ University of Calgary, Calgary, AB, Canada \\ zahra.premji@haskayne.ucalgary.ca
}

Four years ago, an information literacy session in a first-year introduction to business course was transformed from a lecture to a flipped classroom (Althouse, Hedges, Premji, \& Wheeler, 2019). Students watch five online modules prior to class, and then work together in pre-assigned groups during the session to complete worksheet-based activities. The session also incorporates student presentations, or short discussions, between each activity to reinforce the main points. Each of the three activities is allocated a specific amount of time, and the timeline for the session is monitored to ensure completion of all three activities within the 75-minute session. When the class was held in person, students filled out a paper worksheet, and the librarian was able to monitor the progress of each activity by walking around the room, glancing at the paper worksheets, and checking-in with groups as needed.

With the onset of the pandemic, this session had to be adapted for the Zoom environment. The goal for the session was to achieve the same session objectives without sacrificing peer learning and group activities. Breakout rooms in Zoom allowed students to work in small groups; however, a major hiccup was the inability to observe all breakout rooms simultaneously. Each session had approximately 60 students, assigned into groups of six, resulting in ten groups per session. The amount of time it took to join a breakout room, check-in with a group to ensure satisfactory progress, and then move to the next breakout room ranged from 60-120 seconds. Overall, checking-in and responding to requests for help took longer in the virtual environment than in person.

When deciding how to replicate the paper worksheet, options such as Microsoft Word templates, fillable PDFs, and Google Forms were explored. Ultimately, Google Docs was chosen, as it allows students to collaborate and contribute simultaneously, provides a stable link, does not time out or require an account, and has access options that can be changed to restrict further editing after the due date. Students can contribute to a Google Doc anonymously by using an incognito/private browser window as an alternative to logging out of one's Google account. This results in each user being assigned an anonymous animal character which is fun to point out and led to some laughs during the session.

An additional benefit of the platform was the ability to monitor progress, if the Google Docs were appropriately labelled and assigned to specific groups. Prior to the session, each Google Doc was labelled with the group numbers, and the ten Google docs were opened in separate tabs within a browser window. During an activity, monitoring progress was as simple as switching tabs, which was quick and made it easy to identify those groups falling behind. This alleviated some of the time pressures that would have resulted if monitoring of progress were not possible via Google Docs and allowed the librarian time to devote to those groups who require additional help. 
Ticker: The Academic Business Librarianship Review, 5:2 (2021)

http://dx.doi.org/10.3998/ticker.16481003.0005.221

(C)2021 Zahra A. Premji

While there are still elements of the in-person session that have not been replicated entirely in the virtual environment, monitoring progress through the use of Google Docs has solved one of the problems that arose when implementing small group activities. 
Ticker: The Academic Business Librarianship Review, 5:2 (2021)

http://dx.doi.org/10.3998/ticker.16481003.0005.221

(C)2021 Zahra A. Premji

\section{Reference}

Althouse, N., Hedges, P., Premji, Z., \& Wheeler, J. (2019). Mapping the information literacy skills of first-year business students: A journey through lesson study. In M.N. Mallon, L. Hays, C. Bradley, R. Huisman, \& J. Belanger (Eds.), The grounded instruction librarian: Participating in the scholarship of teaching and learning (pp. 201-216). Chicago, IL: Association of College \& Research Libraries. 